\title{
Drivers of and barriers to partner switch in interfirm alliances: a conceptual model
}

\author{
Nina Hampl ${ }^{1,2}$ (D) \\ Published online: 30 November 2019 \\ (C) The Author(s) 2019
}

\begin{abstract}
Historically, research on alliance termination assumes that alliance partners only withdraw from alliances in the event of alliance failure (failure-driven alliance termination). However, recent research on the dissolution of alliances shows that firms also withdraw from alliances through alliance partner switch when they find options with higher match quality than the current partner (option-driven alliance termination). This paper builds on previous work in that field and develops a comprehensive conceptual model of drivers of and barriers to partner switch in interfirm alliances. Based on matching theory, the rectification of alliance partner fit is defined in relation to strategic need, social status and social power as the main drivers and switching costs, social embeddedness and social norms as the main barriers to partner switch. Furthermore, it is argued that market uncertainty and behavioural uncertainty as well as the financial strength and social status of the focal firm have a moderating effect on such drivers and barriers.
\end{abstract}

Keywords Interorganisational relationships - Alliance withdrawal · Partner switch · Switching barriers $\cdot$ Matching theory

JEL Classification $\mathrm{L} 14 \cdot \mathrm{L} 20 \cdot \mathrm{M} 10$

\section{Introduction}

Firms form alliances in order to create or maintain competitive advantage through gaining access to resources such as information, knowledge, practices, technologies and assets not otherwise available to the firms (e.g. Dyer and Singh 1998; Kogut

Nina Hampl

nina.hampl@aau.at

1 Department of Operations, Energy, and Environmental Management, University of Klagenfurt, Universitaetsstrasse 65-67, 9020 Klagenfurt, Austria

2 Institute for Strategic Management, Vienna University of Economics and Business, Welthandelsplatz 1, 1020 Vienna, Austria 
1988; Powell et al. 1996; Teece 1992). The number of alliances has increased over the past decades but empirical evidence shows that the majority of them are unstable and high termination rates prevail (e.g. Inkpen and Beamish 1997; Kogut 1989; Makino et al. 2007; Reuer and Zollo 2005). Typically, literature assumes that firms terminate alliances prior to contract expiration only in the event of failure (Greve et al. 2013; Reuer and Zollo 2005). However, more recent studies on alliance termination show that firms intentionally end alliances earlier if one or both partners' targets are achieved (Reuer and Zollo 2005) or alternative alliance partners with a higher strategic and resource-related fit become available (Greve et al. 2013).

While we already have good insights into why and how firms form alliances (e.g. Dyer and Singh 1998; Eisenhardt and Schoonhoven 1996; Kogut 1988), knowledge regarding alliance termination (e.g. Baker et al. 1998; Greve et al. 2013; Rowley et al. 2005, Seabright et al. 1992) and dynamics (e.g. Doz 1996; Larson 1992; Ring and Van de Ven 1994; Zajac and Olsen 1993) is still limited. A review of the literature shows that firms rarely terminate alliances as a result of acquisition of the partner or joint venture (Hagedoorn and Sadowski 1999; Kogut 1991; Reuer and Zollo 2005). Integrating the alliance partner or joint venture would allow the alliance activities to be continued within the hierarchies of the firm but firms might lack resources or perceive environmental uncertainty as being too high to do so. Instead of integration or full termination of the alliance activities, firms might substitute an alliance with an alternative alliance where they continue similar activities and maintain their access to valuable external resources. Empirical evidence shows that such switching of alliance partners is common practice in several industry sectors. An example is PSA Peugeot Citroën who substituted the joint venture with BMW on hybrid powertrain technology (BMW Peugeot Citroën Electrification) by forming a new alliance with General Motors, which provided a better resource-related fit than the alliance with BMW (Financial Times Deutschland 2012). Furthermore, scholars (Baker et al. 1998; Greve et al. 2010, 2013; Rowley et al. 2005) report high alliance substitution rates (nearly 50 percent) in industries such as investment banking and liner shipping.

To date, however, very little is known about the phenomenon of outside optiondriven withdrawal from alliances (Greve et al. 2013). Learning more about this type of alliance termination would shed more light on what happens after alliance termination and, more generally, increase nascent understanding of post-formation dynamics in interorganizational cooperation agreements. By examining literature on alliance formation, termination and dynamics this paper derives a conceptual model on the antecedents, drivers of and barriers to partner switch in interfirm alliances. ${ }^{1}$

\footnotetext{
1 I build on Lavie's (2006: 639) definition of interfirm alliances ("[a]lliances can take different forms, including joint ventures, franchising, long-term marketing and licensing contracts, reciprocal trade agreements, R\&D partnerships, and affiliation in research consortia") but also include in the definition "interorganizational market relationships" (Baker et al. 1998: 148) as repeated, long-term market transactions with a single or with multiple firms. This definition is also in line with Gulati's (1995b: 620/621) more general definition of an alliance as "any voluntarily initiated interfirm cooperative agreement that involves exchange, sharing, or codevelopment, and it can include contributions by partners of capital, technology, or firm-specific assets".
} 
I define partner switch as the substitution of an existing alliance with an alternative one that provides higher relative net benefit, i.e. the net benefit of switching less the maximum of the net benefits of continuing or terminating, where the net benefit of an option is defined as the difference between the benefits and the costs of an option, both in financial and non-financial terms. It is only if this relative net benefit is positive that partner switch is the most attractive option. ${ }^{2}$

Based on matching theory in alliances (Mitsuhashi and Greve 2009), the net benefit of switching is specifically determined by the match quality with the existing relative to the alternative alliance partner. If match quality with the existing relative to the alternative alliance partner decreases, partner switch becomes an attractive strategic move with regard to continuation and termination. Continuing an alliance by restoring match quality might be a viable option if contractual renegotiations and/or changes in the governance structure (Reuer and Ariño 2002) are generally possible and if the benefits exceed the costs of contractual changes. However, if the strategic need for the alliance has decreased, the costs of continuing the alliance might surpass the benefits and terminating the alliance becomes more attractive. ${ }^{3}$ A fundamental assumption of switching behaviour is the availability of an outside option $^{4}$ (Greve et al. 2013). Thus, it is argued that a mere decrease in match quality in the existing alliance does not necessarily lead to partner switch, but rather to a continuation or termination of the alliance depending on the net benefit of these two options. But if an outside option with a relatively better match quality than with the existing partner is available the prerequisites of partner switch in alliances are met.

In this paper, I define the net benefit of partner switching as a function of drivers of and barriers to switching, where drivers increase and barriers decrease the value to be derived from partner substitution. The decision of a firm to switch its long-term advertising agency depends, for instance, on the "benefits of switching (e.g., better service, higher quality), and the costs of switching (e.g., transaction costs)" (Baker et al. 1998: 153). This assessment is similar to considerations related to cost-benefit/value analyses in discrete alliance formation transactions (Zajac and Olsen 1993), in this case, relativized by the benefits and termination costs of the existing alliance.

This paper builds on prior research on partner switch behaviour and outcomes (Greve et al. 2010, 2013; Mitsuhashi and Greve 2009; Singh and Mitchell 1996) and extends it in several ways. First, taking a different approach to Greve et al. (2013: 83) who focus on the "attractiveness of the focal firm from the viewpoint of a potential

\footnotetext{
${ }^{2}$ It is not a necessary prerequisite of partner switch that the old alliance be (immediately) terminated (Greve et al. 2010). However, existing alliances are deemphasized when new, substituting relationships are formed as e.g. firms are constrained in terms of the resources that they can devote to alliance activities (Singh and Mitchell 1996).

3 This paper only focuses on the conceptualisation of the net benefit of the switching option and does not elaborate on the net benefits of the other options, i.e. continuation or termination of an existing alliance, which is an area for further research.

${ }^{4}$ Forming a new alliance depends on the willingness of the new partner to enter the alliance (bipartite matching, see below for further details). Thus, an outside option is only available if it is also willing to enter a potential alliance with the focal firm.
} 
partner" (perspective of the outside option) and Singh and Mitchell (1996) who investigate the survival of the "old" partner after the focal firm has formed an alliance with a new partner (perspective of the existing partner), this paper specifically sheds light on the focal firm's decision to switch alliance partners. Second, existing studies (Greve et al. 2013; Mitsuhashi and Greve 2009) only focus on resourcerelated criteria in alliance substitution decisions (e.g. market complementarity) but neglect other types of factors such as social drivers (e.g. social status). Thus, compared to previous work in that field, a more comprehensive conceptual model on alliance partner switch decisions is developed, not only focusing on drivers of but also on economic and social barriers to partner substitution as well as on moderators that influence the proposed relationships. Third, besides contributions to the alliance termination and dynamics literature I also provide valuable insights to research on alliance formation. While scholars in that field traditionally assume that firms form alliances on a "green field" (e.g. Hitt et al. 2004; Tyler and Kevin Steensma 1995), this theoretical model elaborates on alliance formation cases where existing partnerships are present. Thus, it suggests that the characteristics of potential alliance partners need to be assessed in relation to the characteristics of the current partner.

The following section provides an overview of the foundational literature on matching theory in social relationships that I further transfer to matching and partner switch in interfirm alliances. In the subsequent sections, I elaborate in more detail on the prerequisites of alliance substitution and develop propositions on the drivers of, barriers to and moderators of partner switch in interorganisational relationships. The paper closes with a discussion of the proposed theoretical model on partner switch in interfirm alliances and provides possible topics for future theoretical and empirical work in that field.

\section{Background literature}

\subsection{Matching theory in social relationships}

Search and matching theory originally comes from economics and was applied to economic and social problems such as job search in labour markets (e.g. Jovanovic 1979; Logan 1996; Simon and Warner 1992) and partner search in human relationships such as marriages (e.g. Cameron 2002; Gale and Shapley 1962; Roth and Sotomayor 1990; Todd 1997). Recently, this theory was introduced to management research on alliance formation and withdrawal on an organisational (Greve et al. 2010, 2013; Mitsuhashi and Greve 2009) and interpersonal level (Vissa 2011).

Matching theory relates to a bipartite search problem ${ }^{5}$ where two heterogeneous actors interact and seek an optimal match between their characteristics that maximizes the value for both actors. Each of the actors has both observable and

\footnotetext{
5 A single actor search or matching problem would be in the context of product search in consumer markets or investment search in financial markets. Here the actor seeks to maximize the utility from the good based on different criteria that match characteristics of the good.
} 
unobservable characteristics (Mitsuhashi and Greve 2009). Observable characteristics may be evaluated in the search process prior to the match. Unobservable characteristics increase match uncertainty as they only reveal themselves after the match. A mismatch related to observable criteria might reflect excessive search costs due to a failure in the search market or bounded rationality of one or both actors (Cameron 2002; Mitsuhashi and Greve 2009). When unobservable characteristics are present, actors perceive mismatches only at a later stage after the match has taken place and thus only have the possibility to ex post withdraw from the match (Mitsuhashi and Greve 2009). In both mismatch cases, the actors will continue their search process for other options with better fit quality. In cases of matching under uncertainty where unobservable criteria exist, both actors look for signals, even weak ones, that provide information or constitute proxies regarding these unobservable characteristics. Such signalling phenomenon in decision making and choice in the case of uncertainty has already been studied in various contexts in management, entrepreneurship and finance literature (e.g. Busenitz et al. 2005; Janney and Folta 2003, 2006; Stuart et al. 1999).

Even though criteria are observable, rational actors might act opportunistically and strategically misrepresent their own characteristics in the search process (Cameron 2002), which again leads to a potential mismatch at a later stage when the actual characteristics are observed. Poor fit quality in matches might also result from a too short and less intensive search process (Cameron 2002). In theory, a fully rational actor that follows an optimization approach would consider and evaluate an infinite number of options for an infinite amount of time. In reality, actors face constraints in terms of capacity and time in their search and evaluation processes. Thus, Simon $(1955,1978)$ postulates that economic models should substitute the outcome optimization requirement (based on fully rational behaviour) for an outcome approximation requirement ('satisficing criterion' or 'satisficing behaviour'). Satisficing actors stop searching when an option meets the adequacy criterion, which considers benefits and costs, the underlying subject and context of the search (i.e. importance). This satisficing behaviour of boundedly rational actors is typically assumed in matching theory (Cameron 2002; Mitsuhashi and Greve 2009).

In search and matching problems involving uncertainty, i.e. in the presence of unobservable criteria, actors seek to optimize their fit and thus benefit through withdrawing and rematching with an alternative actor. However, actors might also withdraw if better options related to observable characteristics become available (Mitsuhashi and Greve 2009). This behaviour assumes a dynamic process of constant evaluation of match quality or match utility. In utility terms, actors thus withdraw if the ex-ante utility exceeds the ex-post utility resulting from characteristics of the match partner (Cameron 2002: 200: Becker et al. 1977; Jovanovic 1979) and withdraw and rematch if the expected utility from an alternative partner exceeds the current ex-post utility from the existing partnership (Mitsuhashi and Greve 2009). ${ }^{6}$

\footnotetext{
${ }^{6}$ This also includes the case where the ex-ante and ex-post utilities from the current partner are equal. Focal actors, however, would still withdraw and rematch as long as the expected utility from the new match is higher.
} 
As shown above, the divergence in utility from the current partnership over time might result from uncertainty related to previously unobservable criteria or failures in the search process. However, a decrease in match quality might also result from a change in the initiating actor's own utility function, i.e. the change in the relative importance of the initiating actor's own search or matching criteria.

\subsection{Matching theory and partner switch in interfirm alliances}

Matching theory in alliance research was formally introduced by the work of Mitsuhashi and Greve (2009) and their investigation of alliance formation in the international liner shipping industry. They argue that in an alliance matching problem, firms seek to optimize two types of fit measures: (1) complementarity (match quality through resource differences) and (2) compatibility (match quality through resource similarities). ${ }^{7}$

The concept of complementarity originally stems from neoclassical economics (e.g. Milgrom and Roberts 1990, 1995) and refers to the phenomenon that "doing more of one activity increases the returns from doing more of another activity" (Parmigiani and Mitchell 2009: 1066). In management literature, it particularly points to the additional or super-additive generation of value by two interrelated resources compared to the sum of the value from each individual resource (e.g. Montgomery and Wernerfelt 1988; Amit and Schoemaker 1993). Firms will thus specifically form alliances with partners whose resources are complementary with the firm's existing bundle of resources and, potentially, also terminate alliances that lack resource complementarity. The objective is to create uniquely complementary bundles of resources (Argyres and Zenger 2012) across firm boundaries that have more value than any alternative combination of these resources. The economic understanding of this concept also refers to the fact that complementary resources are not similar as, per definition, they complement each other. In an alliance context complementary resources might be, for instance, production facilities, R\&D capabilities, market access and knowhow, etc. (Mitsuhashi and Greve 2009).

The concept of compatibility, on the other hand, is mainly used in the technology/IT area and refers to "a situation in which an element can function with other elements in a system without deterioration in overall performance" (Mitsuhashi and Greve 2009: 978). This means that even though resources might be different they share a (or more) common "behaviour" or characteristic, which ensures their functioning in a group. Compatible IT systems run by the alliance partners, for instance, might share the same interface, which ensures the efficiency of communication between the alliance partners. Thus, compatibility in its minimal form

\footnotetext{
7 Complementarity and compatibility have already been discussed in the context of human relationships such as marriages (see e.g. Becker 1974). Becker (1974: 300) talks, for instance, about the complementarity and compatibility of a couple's "time, goods, and other inputs used in household production". Although it is not possible to directly transfer insights from human relationships to organizational relationships there are a number of similarities and scholars have drawn different parallels (e.g. Baker et al. 1998; Peng and Shenkar 2002).
} 
keeps the performance of the alliance partners constant. However, it might also be the case that performance increases through an increase in efficiency. Research on multi-business firms shows that resource relatedness might lead to sub-additive cost effects, i.e. an increase in cost efficiency (Tanriverdi and Venkatraman 2005). In production, the joint production costs of alliance partners with related assets might be lower than the sum of the standalone costs. Compatibility typically relates to functional resources such as production, marketing, human resources, etc. In a "nontechnical" way, compatibility thus also refers to compatible firm cultures and languages (Greve et al. 2013) and compatible targets and strategies of alliance partners. Firms in sales, purchasing or marketing alliances, for instance, have compatible or common targets of efficiency and growth.

Besides resource-related factors, firms also seek fit regarding social criteria. Prior empirical work shows that firms frequently enter into new alliances with current or past alliance partners (Gulati 1999; Gulati and Westphal 1999) where a prerequisite level of trust is given (Hoffmann et al. 2010) and where the partners have been found to be "similar". As "birds of a feather flock together", scholars have also shown a tendency to homophily in interfirm alliances (Rowley et al. 2005). Homophily in status, for instance, increases the likelihood of syndicate formation in investment banking (Podolny 1994) and similarity in firm size decreases the exit rate from investment banking cliques (Rowley et al. 2005). Social similarity "facilitates trust building in interfirm ties and binds partners together" (Rowley et al. 2005: 502). Furthermore, homophily in status might also be due to economic reasons such as, for example, investment banks that cooperate with partners of similar status in order to signal high quality services to clients and capital markets (Chung et al. 2000). Thus, similar firms are more likely to form alliances. Firms, however, might intentionally also seek partners that differ in specific social characteristics, such as social status or social power. This is specifically the case if firms seek to profit from status spillover effects (Podolny and Phillips 1996). Thus, social fit does not exclusively relate to social similarity but also includes social dissimilarity in certain characteristics as long as positive value is generated for both of the actors involved. I therefore add social fit as a third fit measure in an alliance partner matching process besides resource complementarity and compatibility.

I argue that all three fit measures in the matching of alliance partners are orthogonal, i.e. they vary independently of one other, at least to some extent. Thus, any level of one dimension could exist in combination with any level of the other dimensions. In general, the complementarity dimension relates to the "return side" of the equation, i.e. unique complementarity of resources generates super-additive value. In order to achieve unique complementarity, resources need to be heterogeneous (e.g. provide complementary market access). Compatibility of resources (or goals), on the contrary, mainly operates on the "cost side" of the equation as it keeps costs constant or generates competitive advantage through sub-additive costs associated with combined resources (e.g. resource-related production sites or purchase alliances). The third fit dimension, social fit, also relates to the "cost side" of the equation. Non-similarity or a lower fit in the social dimension might lead to an increase in costs as the efficiency of social interaction between the alliance partners decreases e.g. due to power struggles. 
In matching theory terms, alliance partners have observable and unobservable characteristics and the fit measures of complementarity, compatibility and social fit might relate to both. However, they differ in the timing of their appearance. Information on observable characteristics such as market position, status, production and financial resources etc. (Mitsuhashi and Greve 2009) is typically publicly available and can be gathered without interacting with the potential alliance partner. Unobservable partner characteristics include, for instance, whether the potential partner actually sufficiently commits to the alliance and "actually provides the expected resources" during the cooperation period (Greve et al. 2013: 95). These characteristics cannot be verified ex ante to alliance formation, however, alliance partners can agree on contractual arrangements that deal with this uncertainty (Reuer and Ariño 2002; Reuer et al. 2002, 2006; Williamson, 1975, 1985). ${ }^{8}$ Firms also frequently form alliances with direct or indirect ties in order to decrease uncertainty related to unobservable partner characteristics (Gulati 1999; Gulati and Gargiulo 1999; Mitsuhashi and Greve 2009). Alternatively or additionally, alliance partners might pursue the option of optimizing their fit after alliance formation through withdrawing and rematching with an alternative alliance partner.

Utility from the alliance with the new partner (Axelrod et al. 1995) ${ }^{9}$ can only be estimated based on the observable criteria and available signals on the unobservable characteristics, thus, I consider the total expected utility of the new alliance. ${ }^{10}$ With regard to the partner switch phenomenon in interorganisational alliances, the following is assumed: (1) both alliance partners seek to maximize, or more accurately, satisfice, their (expected) utilities; (2) from a macro perspective, the "market for alliances" is not in equilibrium as partner switch permits an increase in the actor's utility from the new alliance, ${ }^{11}$ and (3) non-equilibrium stems from a failure in the search market or bounded rationality of actors (related to observable match criteria), a later mismatch due to a priori uncertainty about unobservable criteria or dynamics in the market that change alliance partners' and outside options' characteristics over time. Partner switch in alliances only takes place if the expected utility of the new partner exceeds the ex-post formation utility of the current partner. I assume that

\footnotetext{
${ }^{8}$ Contractual arrangements can also prevent opportunistic or strategic behaviour of alliance partners related to a misrepresentation of own observable characteristics in the search process. However, contracting between boundedly rational agents is actually always incomplete (Williamson 1979, 1981).

9 Specifics of matching theory in alliance research are that more than two partners might be involved in the matching process. It is also common that firms enter existing multi-partner alliances where the matching problem thus transfers into a 1:n type. An example of this is a firm that seeks to join a standard setting alliance consisting of multiple alliance partners and makes a choice among a set of alternative multi-partner alliances promoting different standards (Axelrod et al. 1995). Another example are investment banks that choose between their membership in different "cliques" whose members frequently collaborate in investment syndicates (Rowley et al. 2005). In this paper, however, I only consider 1:1 matching problems.

10 See Becker (1974) for parallels to the "expected" increase in utility from marriages versus remaining single and Becker et al. (1977) related to the difference between expected and actual utilities in marriages as a reason for divorce.

11 In a market equilibrium, no alliance partner can increase its utility through partner switch as all actors in the market are already in alliances that provide the maximum possible utility.
} 
alliance partners use monitoring systems to periodically evaluate and update their utility estimates from current and potential alliances when new information becomes available in the market (Axelrod et al. 1995; Doz 1996; Hoffmann 2005; Ring and Van de Ven 1994; Zajac and Olsen 1993).

An important prerequisite of partner switch is the availability of an alternative partner that provides a relatively higher utility than the current one. Availability of an alliance partner with higher match quality than the current partner might either result from (1) market dynamics that induce a change in resource distribution among market participants (thus making the outside option more attractive compared to the current alliance partner), or (2) the outside option with higher fit not having been available at the time of matching (e.g. was in another alliance). ${ }^{12}$ As the formation of an alliance is a two-sided social event, it is not just the mere existence of an outside option that is important for partner switch but that the outside option also finds the initiating firm sufficiently attractive to enter the new alliance (Greve et al. 2013). Firms with high social status, for instance, profit from what Eisenhardt and Schoonhoven (1996) call "social opportunity", i.e. higher attraction and thus a higher number of available outside options.

\section{Drivers of partner switch}

Based on previous thoughts on matching theory in interfirm relationships and literature on alliance formation (e.g. Eisenhardt and Schoonhoven 1996), termination (e.g. Baker et al. 1998; Greve et al. 2013; Rowley et al. 2005; Seabright et al. 1992) and dynamics (e.g. Doz 1996; Larson 1992; Ring and Van de Ven 1994; Zajac and Olsen 1993), I derive drivers of partner switch in alliances.

\subsection{Strategic need}

Eisenhardt and Schoonhoven's (1996) findings on strategic and social determinants of alliance formation show that decisions in favour of alliance formation do not solely follow transaction cost considerations but also an initiating firm's strategic need (e.g. in the case of an emerging market with high uncertainty or in highly competitive markets the formation of alliances is more likely). Following Eisenhardt and Schoonhoven's (1996) arguments, firms form alliances when they are in a "vulnerable strategic position" in order to gain access to resources that decrease this negative exposure. In such critical situations, an organisation's criteria and utility function for selecting alliance partners might differ from that in non-critical situations. Thus, on the one hand it could be expected that the utility of that alliance might change with an alteration, and more specifically, an improvement in the strategic position of the focal firm (e.g. market share increase in an emerging market). On the other

\footnotetext{
12 This assumes that outside options are in general available. In the case of oligopoly market structures outside options might be limited or generally unavailable, which constitutes a fundamental barrier to partner switch.
} 
hand, also in non-critical situations a partnering firm's strategic need might alter over time, which might lead to a decrease in match quality of the current alliance as a result of arising complementarity or compatibility issues (Doz 1996; Greve et al. 2013; Koza and Lewin 1998; Reuer and Ariño 2002). For instance, if firms adopt a strong innovation-driven or explorative strategy they require more and different resources (e.g. in the form of financial resources, R\&D skills and capabilities) and thus alliance partners than for efficiency-driven or exploitative strategies (Eisenhardt and Schoonhoven 1996; Koza and Lewin 1998).

If the resource needs of a firm change this also reduces the dependence on a specific provider of those resources (Baker et al. 1998; Pfeffer and Salancik 1978). Therefore, I expect a positive correlation between a firm's change in strategic need, and thus a change in the strategic fit between the alliance partners, and the likelihood of partner switch. From a matching theory perspective, a potentially resulting mismatch in the alliance partners' resource combinations can arise on the complementarity or compatibility dimension (or both). In such a situation, the partner switch option increases in attractiveness if an outside option is available whose strategic fit to the focal firm is higher than the strategic fit of the current partner. I thus propose:

Proposition 1a. The higher the resource complementarity with the potential new partner relative to the current partner, the higher the likelihood of partner switch.

Proposition $1 \mathrm{~b}$. The higher the resource compatibility with the potential new partner relative to the current partner, the higher the likelihood of partner switch.

\subsection{Social status}

Research shows that firms that form alliances with high-status partners gain in terms of their own social status (Podolny and Phillips 1996). High social status is commonly associated with superior "quality" and performance (Lynn et al. 2009; Podolny 1993; Washington and Zajac 2005). The status of a producer, for instance, might act as a signal of product quality (Podolny 1993). A firm's status is determined by its resource endowments, its behaviour in the market, its relational network such as ties to prominent suppliers or consumers (Podolny 1993; Ahuja 2000a) and performance indicators such as market share, sales and profits (Fombrun and Shanley 1990). In this sense, status is quite similar to the concept of reputation. In industries there typically exist so-called status hierarchies (Lynn et al. 2009), i.e. rankings of industry participants according to their status. Thus, different subgroups or segments of suppliers with distinct characteristics can emerge that share a similar status in the market (Podolny 1993). Firms seek to advance their ranking in the status hierarchy, mainly due to the interrelation between status and market performance (Benjamin and Podolny 1999). Furthermore, firms tend to collaborate with firms from the same status hierarchy level, i.e. they prefer homophily within their network (Chung et al. 2000; Podolny 1994). 
With regard to the switching phenomenon, a lower match quality related to social status might emerge in the existing alliance if the current alliance partner experiences a loss in social status (e.g. due to bankruptcy, fraud etc.). In such a case, the likelihood of alliance withdrawal increases as the result of a need to prevent negative spillover effects from the current alliance partner (Jensen 2006). Further, a mismatch in social status between alliance partners might result from an increase in the focal firm's status as this would lead to an improvement in the status hierarchy ranking of that firm. I assume that in both situations the propensity to switch the alliance partner increases if an outside option with higher fit in social status is available. I argue that fit in social status might relate to either (1) fit in terms of status dissimilarity where firms seek alliances with alternative partners of higher social status as they perceive status as a proxy for "quality" or want to increase their own reputation or legitimacy through a positive spillover effect or (2) fit in form of status similarity ("birds of a feather flock together") where firms substitute alliance partners of lower social status with outside options of the same status hierarchy level. I therefore state:

Proposition 2. The higher the social status of the potential new partner relative to the current partner, the higher the likelihood of partner switch.

\subsection{Social power}

Power imbalance that stems from dependence in a relationship is an important driver of alliance dynamics (Baker et al. 1998) as firms typically seek to decrease or eliminate dependence on resources and alliance partners and thus uncertainty in an interfirm relationship (Pfeffer 1972; Pfeffer and Salancik 1978). For instance, clients might be dependent on a specific supplier in a sourcing alliance. In order to rectify this power imbalance, clients might switch their supplier (Baker et al. 1998), thus entering into an alternative sourcing alliance. Asymmetry in power and dependence might result for example from difference in firm size (Baker et al. 1998) or network position (Podolny 1993), where relative power of the partners in the relationship typically increases with size and a better network position. The more powerful partner is able to drive the relationship in its own interest and negotiate a higher share of the value generated from the alliance with potential negative consequences for the less powerful partner (Greve et al. 2010; Lavie 2007; Pfeffer and Salancik 1978).

Resource dependence theory suggests that firms absorb dependence in a relationship through a change in the governance form, i.e. in case of an alliance, through a merger or acquisition of the alliance partner (Pfeffer and Salancik 1978). ${ }^{13}$ However, recent conceptual advances by Casciaro and Piskorski (2005: 168) suggest that firms only acquire or merge in the case of "mutual dependence", i.e. the alliance partners are equally strongly dependent on each other. Power imbalance, i.e. the difference in the alliance partners' levels of power, on the contrary, decreases the likelihood of power absorption through changes in ownership. An alternative move that is not

\footnotetext{
13 Pfeffer and Salancik (1978) perceive non-ownership mechanisms such as alliances as weaker forms of power absorption than ownership-based governance forms such as mergers and acquisitions.
} 
discussed by Casciaro and Piskorski (2005) and only briefly mentioned by Seabright et al. (1992) is to eliminate the power imbalance in the current relationship through partner switch: the less powerful organization terminates the alliance and forms a new alliance with an equally or (relatively) less powerful partner. I thus state:

Proposition 3. The lower the social power of the potential new partner relative to the current partner, the higher the likelihood of partner switch.

\section{Barriers to partner switch}

Partner switch also involves barriers that arise from legal, financial, social and structural commitments and constraints (Greve et al. 2013; Rowley et al. 2005). The concept of switching barriers is not new to strategic management literature: Gimeno et al. (1997: 754), for instance, elaborate on exit or switching barriers in the context of entrepreneurial exit decisions. They argue that entrepreneurs exit their business if the "expected utility of alternative employment (...) minus the cost inherent in switching $(. .$.$) exceeds the revised expected utility of remaining in the entrepre-$ neurial venture" and define switching costs as search costs and psychological costs related to job security. Furthermore, my conceptualization of switching barriers is to some extent similar to the logic of market exit (Porter 1980) and entry (Caves and Porter 1977) barriers.

In this context, I differentiate between three types of switching barriers: (1) financial barriers such as sunk costs from the current cooperation, contractual and negotiation costs related to the termination of the current alliance and the formation of the new alliance etc. (switching costs); (2) structural barriers resulting from high social embeddedness in e.g. high-density networks; and (3) social barriers such as social norms prevailing in the alliance partners' network that decrease the incentive for partner switch.

\subsection{Switching costs}

Financial barriers in alliance partner switch are mainly based on transaction cost logics (Williamson 1975). I distinguish between two different kinds of switching costs: (1) investments and financial commitments that have been made in the current alliance or potential costs related to contract termination such as penalties (costs related to alliance termination); and (2) transaction costs incurred for entering the new alliance (costs related to alliance formation). Costs related to alliance termination and subsequent alliance formation depend on the type, intended purpose and duration of the alliance. Relationship-specific investments are typically lower for supplier-buyer relationships, manufacturing agreements, licensing agreements and marketing alliances (e.g. human capital-related investments or the establishment of a new subsidiary close to the alliance partner) than for R\&D and product development alliances where both partners are more intensively involved in the cooperation, often in the form of equity joint ventures (Eisenhardt and Schoonhoven 1996; Reuer and Ariño 2002). 
R\&D and technology joint ventures typically involve transfer of tacit knowledge through close collaboration (Kogut 1988; Polanyi 1967). Tacit knowledge, as compared to explicit knowledge, cannot (easily) be codified or exchanged through market mechanisms or other types of non-hierarchical governance forms as it is embedded in the organisations (Kogut 1988), individual skills and experiences and sometimes within complex organisational routines (Szulanski 1996). Therefore, the transfer of tacit knowledge is slow and costly (Kogut and Zander 1996) and requires sufficient commitment and investment by both partners. Furthermore, it is difficult to measure the transfer of tacit knowledge in interfirm collaboration. R\&D and technology alliances are also more likely to involve investment in specialized assets including "physical assets like plant and equipment and also site specificity, human asset specificity, and dedicated assets" (Parkhe 1993: 805). Terminating such alliances might create loss in value of these assets if it is not possible or too costly to reassign them to other purposes or to transfer them to other alliances (Williamson 1981, 1985). Due to this specificity of assets, the partners become structurally locked into the alliance. Relation-specific assets accumulate over time and thus barriers for partner switch that relate to cospecialized assets are usually higher for "older" alliances than for "younger" ones (Fichman and Levinthal 1991) at least until such time as these investments have been amortized through payoffs from the alliance (Parkhe 1993).

In matching theory, $\mathrm{R} \& \mathrm{D}$ and technology alliances thus involve higher levels of uncertainty due to the unobservability of key characteristics of the alliance partner that only unfold in the course of the cooperation, such as the actual commitment and investment by the alliance partner to exchange critical knowledge (Greve et al. 2013). Such alliances are thus more vulnerable to opportunistic behaviour by one of the alliance partners (Gulati 1995a; Gulati and Singh 1998). Therefore, if partner switch takes place in an alliance where tacit knowledge transfer and asset specificity is high, firms will seek to also negotiate a contract with the new alliance partner that eliminates or decreases the likelihood of misbehaviour in the alliance that may lead to a decrease in the value of specific investments and assets (e.g. through penalties) (Poppo and Zenger 2002; Reuer and Ariño 2002). For such (often equity-based) alliances, initiation and contracting costs are typically high due to intensive and lengthy negotiations (Gulati 1995a). A new equity-based alliance might also involve the setting up of a new firm (joint venture), with its own organisation and governance structure (Gulati 1995a). Costs related to new alliance formation, however, depend on the switching firm's experience with alliances as well as its alliance initiation and management capabilities (Hoffmann 2005). Firms with strong initiation and management capabilities are able to decrease these types of transaction costs due to an increase in efficiency. Alliance formation costs also depend on the availability of an alternative partner. If firms substitute alliance partners with already existing partners from their network costs for search, selection and evaluation are rather low. However, if outside options are not readily available such type of costs might be considerably high (Mellewigt and Decker 2014). Considering the sum of the switching costs (for terminating the old alliance and entering the new partnership), I propose: 
Proposition 4. The higher the switching costs, the lower the likelihood of partner switch.

\subsection{Social embeddedness}

Foundational work by Granovetter (1985) introduces the concept of social embeddedness, which shows that organisations are embedded in a network of social relations that impact their behaviour and performance (Gulati et al. 2011; Rowley et al. 2005) "by constraining the set of actions available to the individual actors" (Marsden 1981: 1210). Scholars have provided empirical evidence for the impact of interfirm networks on, for instance, an organisation's innovation output (Ahuja 2000b), the formation of new alliances (Gulati 1999; Gulati and Westphal 1999) and whole networks (Walker, Kogut and Shan 1997), organisational learning (Dyer and Hatch 2006; Powell et al. 1996) and firm reputation (Stuart, Hoang, and Hybels 1999).

Social embeddedness can be an important source of economic performance due to the advantages of trusting relationships but can also lead to social obligation and may constrain the opportunity set firms perceive, which may negatively affect organisational performance (Uzzi 1997). In the context of alliance partner switch, I follow Greve et al. (2013) and adhere to the view of an intermediate social embeddedness (Granovetter 1985) where "firms' decision makers are neither oversocialised "cultural dopes" whose behaviour is completely determined by their social context nor undersocialised "atoms" free of social constraints" (Greve et al. 2013: 79). This assumption is important as otherwise partner switch would not be possible as barriers arising from social embeddedness would always be too high. Firms do, however, to some extent, bear social risk such as negative reputation due to the individual strategic goals that they follow.

\subsubsection{Intra-alliance social embeddedness}

Seabright et al. (1992) and other alliance researchers (e.g. Levinthal and Fichman 1988; Luo 2001) investigate the social phenomenon of "attachment" that emerges in alliances over time on an individual and organisational level. Seabright et al. (1992: 126) define it as "an inertial or binding force between exchange partners that can lead to the maintenance of an existing relationship to the exclusion of alternatives". Furthermore, Greve et al. (2010: 309) indicate a decreasing effect of "experiential cohesion" on withdrawal probability, which they describe as intra-alliance social embeddedness that mainly stems from "trust and collaboration experience" in alliances over time. I therefore argue that attachment and cohesion specifically hinder partner switch in long-term alliances (alliances that have passed the "honeymoon period"; Fichman and Levinthal 1991; Levinthal and Fichman 1988) and alliances whose partners have several parallel alliances or exchange relationships due to inertia and "social lock-in". Thus, even in cases where the incentive to switch partners trumps inertia due to attachment and cohesion, partner switch might lead to a loss in trust related to alliance commitment and might destabilize other current alliances between these firms and decrease the likelihood of future alliances. An example 
would be a client-auditor relationship where the auditor also provides tax advice and business consulting services to the same client (Seabright et al. 1992). A provider switch in one of the services may have an impact on the other exchange relationships between those firms. Considering these two effects, inertia and potential negative spillover, I argue:

Proposition 5. The stronger the ties between the alliance partners, the lower the likelihood of partner switch.

\subsubsection{Network-related social embeddedness}

If the partners have common ties to other firms they are more socially and structurally embedded than if a large number of structural holes, i.e. disconnections between a firm's direct ties (Burt 1992), exist. A large number of structural holes provide firms with benefits from information brokerage between disconnected network partners or clusters. In cohesive networks with a high number of connections, information thus flows faster and more easily than in networks where some firms hold strong brokerage positions. The extreme case of a cohesive network or sub-network is to be regarded as a "clique" where all members are connected (Kenis and Knoke 2002) and where this high density of ties even acts as a "governance mechanism" (Rowley et al. 2005: 501) to prevent opportunistic behaviour by one of the clique members. Such dense networks are characterized by multiplicity and interdependence in relationships, i.e. multiple past or current ties between network members that emerge over time. Research on tie formation shows that firms tend to enter into alliances with past direct or indirect ties as information about these organisations is more readily available and credible (Gulati and Gargiulo 1999).

I therefore argue that partner switch depends on how strongly the two firms in the alliance are structurally embedded, i.e. how many indirect ties between the two partners exist. If the number of indirect ties is high (i.e. there are few structural holes) the incentive for partner switch is low. Due to the high structural embeddedness of the initiating firm there is increased probability that a partner switch in the focal alliance has a negative spillover (e.g. negative economic consequences due to interrelation and loss in trust) on other alliances of that firm in the network.

Proposition 6. The higher the density of the alliance partners' network, the lower the likelihood of partner switch.

\subsection{Social norms}

A fundamental question is whether partner switch is seen as malfeasance within the network or clique and sanctioned. Dense interaction between network members drives the emergence of rules and norms that govern the behaviour of network members (Gulati et al. 2000; Rowley et al. 2005). They might be of formal (e.g. in writing such as in the form of contracts) or of informal (common understanding) nature (Gulati et al. 2000). Partner switch decisions are thus influenced by such prevailing social rules and norms. Baker et al. (1998), who analyse 
buyer-seller relationships in the advertising services market, discuss different rules of exchange that govern switching behaviour and either lead or do not lead to sanctions. The two extreme types of rules consist of those that favour "free and easy", and thus frequent switching, and rules that build on "exclusivity" or "loyalty", which lead to infrequent switching (Baker et al. 1998: 150/151).

Levinthal and Fichman (1988) investigate U.S. client-auditor relationships and show that switching of auditors is very low (less than 4 percent; Seabright et al. 1992: 129). The reason for this behaviour is that each public organisation is required by law to engage an independent auditor that provides public opinion about the organisation's financial statements. Even though the legal and formal barriers for switching are low, due to the sensibility of this service each change of auditor would generate suspicious sentiments among third parties and thus drives the exclusivity of client-auditor relationships. In the advertising services market that Baker et al. (1998) studied, sourcing is not influenced or restricted by legal obligations but by "old", exclusivity and loyalty-based rules of exchange.

Different from these market-based exchange relationships, Greve et al. (2010, 2013) studied interfirm alliances in the form of vessel-sharing agreements in the global liner shipping industry. Despite alliances in that industry being openended and costly to terminate, rates of withdrawal and switch of alliances are considerably high. They found that 48 percent of firms entered new, substituting alliances within a year of alliance termination. Other markets such as investment banking also encourage frequent switching (Baker et al. 1998). Rowley et al.'s (2005: 514) study on exit rates in investment banking cliques shows an equally high number of partner switches as that conducted by Greve et al. (2010, 2013): 47 percent of the firms exit and subsequently enter new cliques within 2-5 years. Based on the theoretical arguments and empirical evidence outlined in this section, I propose:

Proposition 7. Social norms that favour exclusivity or loyalty among alliance partners decrease the likelihood of partner switch.

\section{Moderating effects of industry, alliance and firm-specific characteristics}

Literature shows that industry, alliance or firm-specific characteristics influence strategic decisions of interconnected firms, as seen for example in the impact of uncertainty on the selection of alliance partners (Beckman et al. 2004) or the influence of social status on the number of potential alliance partners (Eisenhardt and Schoonhoven 1996). In this model, I consider (1) market uncertainty (industry level), (2) behavioural uncertainty (alliance level), (3) financial strength of the focal firm (firm level) and (4) social status of the focal firm (firm level) as moderators of the proposed relationships. 


\subsection{Market and behavioural uncertainty}

In the model on alliance partner switch, I regard environmental and behavioural uncertainty ${ }^{14}$ as being two distinct moderating effects as literature shows that different forms or sources of uncertainty have a varying impact on governance decisions (e.g. Dyer 1996; Sutcliffe and Zaheer 1998). Scholars emphasize, for instance, that high behavioural uncertainty between exchange partners, in particular supply uncertainty, favours a hierarchical governance mode (Walker and Weber 1984; Sutcliffe and Zaheer 1998) in order to mitigate or decrease the risk of opportunistic behaviour, whereas high technological uncertainty increases the efficiency of the market mechanism and hybrid governance forms due to greater flexibility (Balakrishnan and Wernerfelt 1986; Dyer 1996; Robertson and Gatignon 1998). With regard to high demand uncertainty, scholars have found conflicting results with an increased likelihood of integration (Walker and Weber 1984, 1987) or a higher preference for flexibility and thus non-integration (Harrigan 1986). ${ }^{15}$

In literature on uncertainty in strategic alliances, scholars show that under conditions of high market uncertainty (i.e. uncertainty related to "consumer demand, industry-level technology trajectories and standards, input costs, and the general competitive climate", Beckman et al. 2004: 262) firms tend to follow an "exploitation" strategy by reinforcing their existing network through additional tie formations with current partners (Beckman et al. 2004). Uncertainty exogenous to the firm and alliance cannot or can only to a limited extent be influenced by the firm (Folta 1998). In this model, I thus assume that a high level of market uncertainty has a weakening effect on the attempt of firms to rectify fit in strategic need, i.e. fit in resource complementarity and resource compatibility, through alliance partner switch. In an environment of high market uncertainty, firms tend to continue the alliance with the current partner despite a misfit of resources, as it is unclear if the environmental uncertainty might change the situation again in the (near) future. A partner switch, thus, might only lead to sustaining net benefits in comparison with continuing or terminating if uncertainty related to immediate future market change is low. I therefore propose:

Proposition 8a. The higher the market uncertainty, the lower the positive effect of resource complementarity of the potential new partner relative to the current partner on the likelihood of partner switch.

Proposition $8 \mathrm{~b}$. The higher the market uncertainty, the lower the positive effect of resource compatibility of the potential new partner relative to the current partner on the likelihood of partner switch.

\footnotetext{
14 I define uncertainty as the "difficulty firms have in predicting the future, which comes from incomplete knowledge" (Beckman et al. 2004: 260).

15 It seems that if demand uncertainty is particularly related to volume uncertainty instead of or in addition to technological uncertainty (Walker and Weber 1984), then integration might be more favourable. Otherwise, market and hybrid governance modes provide higher performance.
} 
I argue that uncertainty on an alliance level (as reflected, for example, in behavioural uncertainty) specifically moderates the social fit indicators in this model on alliance partner switch. In accordance with Santoro and McGill (2005), I define behavioural uncertainty as partner and task uncertainty. Firms seek to negotiate contracts with alliance partners to reduce behavioural uncertainty. Furthermore, literature on strategic alliances also shows that experience with the alliance partner increases trust over time and thus decreases perceived uncertainty about the future behaviour of the partner and, as a consequence, the need for monitoring and control (Gulati 1995a; Larson 1992; Santoro and McGill 2005).

Previous work on trust in interfirm relationships focused on the emergence of trust but neglected the reasons and consequences of a decline in trust. Peng and Shenkar (2002: 97) provide empirical evidence on tie dissolution as a consequence of declining trust from the automotive industry by showing that "previously trusting parties become "intimate strangers," setting in motion the downward spiral toward eventual dissolution". Although adequate control mechanisms can partly compensate for low trust in alliances, it is known that contracting between boundedly rational agents is always incomplete (Williamson 1979, 1981) and a certain minimum level of trust is required for the functioning of an interfirm cooperation (Das and Teng 1998). Thus, I argue that if trust in the current alliance partner decreases behavioural uncertainty increases, which has a reinforcing effect on the aspiration to rectify misfit in social status or social power through partner switch. I thus state:

Proposition 8c. The higher the behavioural uncertainty, the higher the positive effect of social status of the potential new partner relative to the current partner on the likelihood of partner switch.

Proposition $8 \mathrm{~d}$. The higher the behavioural uncertainty, the higher the negative effect of social power of the potential new partner relative to the current partner on the likelihood of partner switch.

\subsection{Financial strength of the focal firm}

The severity of switching costs depends on the focal firm's alliance management experience and capabilities (Hoffmann 2005). However, the impact of financial switching barriers also depends on the financial resources of the firm: if a firm has high financial strength it can deal more easily with high switching costs than a firm with low financial strength. I therefore argue:

Proposition 9. The higher the financial strength of the focal firm, the lower the negative effect of switching costs on the likelihood of partner switch.

\subsection{Social status of the focal firm}

In this model, I introduce the rectification of social status fit as a driver of alliance partner switch where the positive difference between the social status of the outside option and that of the current alliance partner are considered as the determining 
factor. However, I also argue that the social status of the focal firm that considers switching the alliance partner has a moderating effect on the social barriers in this model, i.e. the intra-alliance and network-related social embeddedness of the alliance partners and the prevailing social norms. From studies in sociology it is known that high-status actors are more likely to deviate from prevailing group norms as they feel more secure in their social position, have more resources and better access to information (Becker 1970; Hollander 1958; Phillips and Zuckerman 2001). Phillips and Zuckerman (2001), for instance, found high middle-status and low highstatus conformity with rules in two markets (legal services and investment advice). I thus assume that high-status firms are more able and willing to deal with negative social consequences from alliance partner switch and propose:

Proposition 10a. The higher the social status of the focal firm, the lower the negative effect of intra-alliance social embeddedness on the likelihood of partner switch.

Proposition 10b. The higher the social status of the focal firm, the lower the negative effect of network-related social embeddedness on the likelihood of partner switch.

Proposition 10c. The higher the social status of the focal firm, the lower the negative effect of social norms on the likelihood of partner switch.

\section{Discussion and future research}

In this paper I sought to develop a conceptual model of drivers of and barriers to partner switch in interfirm alliances. Matching theory provides a fruitful and promising perspective on this phenomenon to derive its antecedents in interorganisational relationships. The main driver of partner switch in alliances is thus the desire to rectify misfit and imbalance related to an alliance partner's match attributes such as the complementarity and compatibility of resources in order to fulfil strategic needs and in relation to social factors such as social status and power. Firms enter alliances based on a strategic need such as access to valuable resources that are not otherwise available to them (e.g. Dyer and Singh 1998). If different exogenous factors change this underlying need then the complementarity or compatibility of the alliance partners' resources might be threatened, and firms might seek to restore complementarity or compatibility by alliance partner switch. But imbalance might also emerge on the social dimension of the alliance: in this case, partner switch might be a viable option in order to rectify fit in social status and power as, for example, differences might lead to negative spillovers on reputation (Podolny 1993; Podolny and Phillips 1996) or have a negative impact on performance (Greve et al. 2010; Pfeffer and Salancik 1978) for the more vulnerable alliance partner. Another prerequisite of partner switch in interfirm alliances is the availability of a relatively more attractive outside option aligned to the match attributes relevant to the focal firm.

Equally as important as drivers, however, are barriers that constitute the flipside of the partner switch coin. Partner switch in interfirm alliances entails financial, 


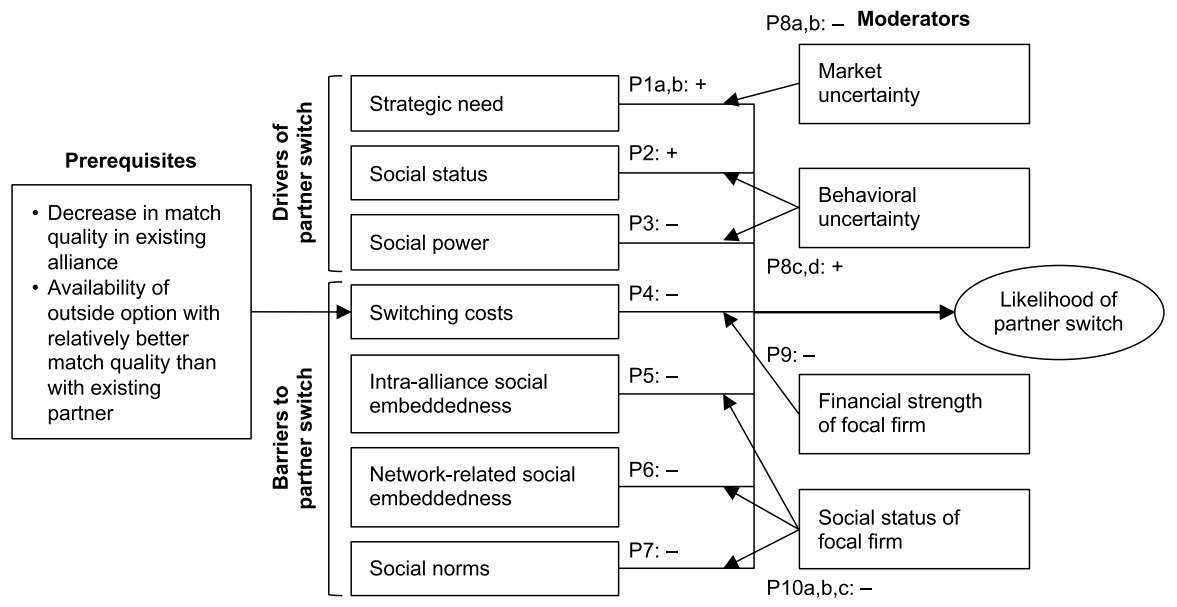

Fig. 1 Conceptual model of drivers of and barriers to alliance partner switch

structural and social barriers that relate to the termination of the old alliance and the subsequent formation of the new alliance. Financial barriers to partner switch (switching costs) are higher for R\&D and technology-related alliances as these types of alliances typically involve high levels of investment in the transfer of tacit knowledge and co-specialized assets and considerable contractual arrangements and costs to prevent opportunistic behaviour by one of the parties. Furthermore, firms are embedded in social networks of interorganisational relationships that impact their behaviour (Gulati et al. 2011) due to social and structural interrelations and social norms and thus have a strong influence on their decision to switch alliance partners. I also consider moderating effects that influence the proposed relationships: market and behavioural uncertainty mainly impact the switching drivers in the conceptual model, while market uncertainty has an attenuating effect on resource-related fit measures and behavioural uncertainty a reinforcing effect on social fit measures. The focal firm's financial strength and social status specifically moderate the influence of switching barriers, while firms with high financial strength and high social status perceive lower switching barriers than firms in less favourable positions.

I argue that partner switch potentially takes place if the net benefit of switching (the difference between the benefits and costs of switching) is higher than either the net benefit of continuing or terminating. The threshold of how much higher the relative net benefit needs to be will need to be defined by the focal firm based on its references for similar strategic decisions and investments. Threshold levels determine the decision to pursue one of the three options and are expected to differ across firms. The landmark article by Gimeno et al. (1997) shows, for instance, that firmspecific thresholds of performance have a significant impact on the decision to exit an entrepreneurial business and thus on firm survival. Furthermore, I point out that while the major share of the costs involved in partner switch occurs at once (at the 
point in time when the old alliance is terminated and the new alliance is formed), ${ }^{16}$ the majority of the benefits are generated over the duration of the new alliance. This is why this paper argues that firms can only act upon the expected utility from the new alliance relative to the existing one.

The conceptual model related to partner switch in alliances is summarized in Fig. 1 below.

This paper provides several contributions to literature. First, scholars in the field (Greve et al. 2010, 2013; Mitsuhashi and Greve 2009; Singh and Mitchell 1996) have either focused on the current alliance partner's or the outside option's point of view while neglecting to provide a detailed perspective on the focal firm's decisionmaking logics relating to the decision on whether to pursue an outside option over an existing alliance. Learning more about managers' decision policies over the lifetime of an alliance would help to extend nascent understanding of post-formation dynamics in interorganisational relationships. Specifically, this paper conceptually sheds more light on outside options as contextual factors that shape alliances besides frictions that might arise within the alliance relationship (e.g. opportunistic behaviour of one of the partners). In doing so, I provide valuable contributions to the development of an evolutionary theory of alliance management beyond the lifecycle of a single alliance.

Second, I see this conceptual model on partner switch in interfirm alliances as a natural extension of Greve et al.'s $(2010,2013)$ work that in particular investigates drivers of alliance termination and partner substitution. This paper extends this perspective on drivers and brings barriers and moderators as main constituents of the partner switch phenomenon into the spotlight of analysis. Furthermore, existing studies (Greve et al. 2013; Mitsuhashi and Greve 2009) only consider resourcerelated factors (e.g. market complementarity) as determinants of alliance partner switch. Rectifying resource fit in alliances through partner switch impacts the value created from a firm's alliance activities. However, I perceive social factors as equally important inducements of option-driven withdrawal. For instance, several scholars have shown how the social status of a firm's affiliates affects its own status in the industry (e.g. Benjamin and Podolny 1999; Podolny and Phillips 1996) and that social power determines the bargaining power of alliance partners and eventually how much value each of them can appropriate in the alliance (Greve et al. 2010; Pfeffer and Salancik 1978). Thus, not considering social factors might potentially lead to a biased perspective on option-driven termination decisions.

Third, extant work on alliance formation assumes that new alliances are formed on a "green field". However, I argue in this paper that a certain percentage of these new alliances are actually partner switches where firms substitute existing interorganisational collaborations. Empirical work shows that some $50 \%$ of new alliance formations in certain industries (Greve et al. 2010, 2013; Rowley et al. 2005) may fall into this category. This insight might help to shed light on potential heterogeneity in decision-making criteria applied by alliance managers to assess and select new

\footnotetext{
${ }^{16}$ However, this excludes "social costs" e.g. in the form of foregone business opportunities due to negative reputation.
} 
collaboration partners. Alliance managers that substitute existing alliances evaluate the characteristics of potential partners not only relative to other alternative partners but also relative to the current partner.

In order to stimulate further research on the partner switch phenomenon, I seek to highlight some promising topics in the following paragraphs. In this paper, I derived a set of different drivers of and barriers to partner switch in interfirm alliances as well as factors that are proposed to moderate these relationships. Future research needs to empirically test this conceptual model and contribute to its further theoretical development. Intriguing questions would include for instance: which of the main effects on the likelihood of partner switch is stronger? Do drivers have a stronger effect than barriers, or vice versa? What types of barriers are stronger if specific drivers are present? Tyler and Steensma (1995), for instance, provide some initial insights on the relative weighting of the drivers and highlight, for example, that opportunity-related criteria (e.g. significance of technology to firm strategy) are more relevant for executives' assessment of technological collaboration opportunities than certain social factors (e.g. compatibility of management styles). I thus assume that strategic need has a stronger impact on the propensity to switch the alliance partner than social status and social power. Nevertheless, as shown in literature, both of the two social factors are assumed to have a relevant effect on switching likelihood. Related to the barriers, work by Greve et al. (2010) shows that only relational embeddedness (prior ties between alliance partners) as compared to structural embeddedness had a negative effect on withdrawals from alliances. Based on this finding, I assume that intra-alliance social embeddedness will be a stronger barrier to alliance partner switch than network-related social embeddedness. Furthermore, Seabright et al. (1992) found that attachment also attenuates the effect of resource misalignment on the likelihood of tie dissolution. Although I mentioned potential interrelations between some drivers or barriers, I did not systematically theorize on interactions between particular drivers or barriers, which leaves room for future scholarly work in this field.

Of considerable interest is also the ambivalent role of the focal firm's ego network of direct and indirect organisational ties. Scholarly work on alliance formation has shown that firms prefer to form ties with partners from their network (Gulati 1999; Gulati and Westphal 1999). If such an alliance breaks and if the ex-ante match quality with that partner was high, it might also be high with an alternative partner from the same network that the current partner stems from (Mitsuhashi and Greve 2009), which is actually the same as the focal firm's network. Thus, if all three of the actors belong to the same network, it provides attractive options that drive partner switch while at the same time constituting a social barrier as sanctions for misbehaviour might be high, depending on the social norms that prevail in the network. Future work might specifically want to shed light on the thought processes of alliance partners facing such trade-offs in partner switch.

Closer examination of time effects in alliance partner switch, described by Levinthal and Fichman (1988) and Baker et al. (1998) as the "honeymoon effect", in relation to tie dissolution may also prove worthwhile: in the early stages of a partnership or exchange relationship, the risk of termination increases with time and after a tipping point (end of the "honeymoon" period) the rate of dissolution decreases 
with time. This effect is also found in Rowley et al.'s (2005) study on members' exit rates in investment banking cliques. Levinthal and Fichman's (1988) explanation of this effect is that relationship-specific assets develop over time and lock the partners into their existing relationship. Thus, I assume that the likelihood of partner switch might be higher in the early years of an alliance and then continuously decrease after a tipping point.

A further avenue for future research might be the extension of the conceptual model in this paper from a 1:1 to a 1:n partner switch type, or vice versa: under specific circumstances firms may substitute a single alliance with two or more alliances, or vice versa, and it is already known that firms frequently switch cliques (Axelrod et al. 1995; Rowley et al. 2005). Some of the drivers discussed in this paper may directly be transferred to "clique switching": Rowley et al. (2005), for instance, investigate the drivers of firm exits from investment banking cliques, an industry with a relatively high rate of switching between cliques. They conclude that members are more likely to exit if diversity in member size increases, whereas density of clique contacts, role diversity in cliques and the equal access to structural holes (to appropriate sufficient value share) decrease exit rates. Thus, match quality on compatibility (e.g. firm size) and complementarity (e.g. role) of partners' attributes also seems to be relevant in a clique context and imbalances in these dimensions may drive clique switching.

Acknowledgements Open access funding provided by University of Klagenfurt.

Open Access This article is distributed under the terms of the Creative Commons Attribution 4.0 International License (http://creativecommons.org/licenses/by/4.0/), which permits unrestricted use, distribution, and reproduction in any medium, provided you give appropriate credit to the original author(s) and the source, provide a link to the Creative Commons license, and indicate if changes were made.

\section{References}

Ahuja G (2000a) The duality of collaboration: inducements and opportunities in the formation of interfirm linkages. Strateg Manag J 21(3):317-343

Ahuja G (2000b) Collaboration networks, structural holes, and innovation: a longitudinal study. Adm Sci Q 45:425-455

Amit R, Schoemaker PJH (1993) Strategic assets and organizational rent. Strateg Manag J 14:33-46

Argyres NS, Zenger TR (2012) Capabilities, transaction costs, and firm boundaries. Organ Sci 23(6):1643-1657

Axelrod R, Mitchell W, Thomas RE, Bennett DS, Bruderer E (1995) Coalition formation in standardsetting alliances. Manag Sci 41:1493-1508

Baker WE, Faulkner RR, Fisher GA (1998) Hazards of the market: the continuity and dissolution of interorganizational market relationships. Am Sociol Rev 63:147-177

Balakrishnan S, Wernerfelt B (1986) Technical change, competition and vertical integration. Strateg Manag J 7(4):347-359

Becker MH (1970) Sociometric location and innovativeness: reformulation and extension of the diffusion model. Am Sociol Rev 35(2):267-282

Becker GS (1974) A theory of marriage. In: Schultz TW (ed) Economics of the family: marriage, children, and human capital. University of Chicago Press, Chicago, pp 299-351

Becker GS, Landes EM, Michael RT (1977) An economic analysis of marital instability. J Polit Econ 85(6):1141-1187 
Beckman CM, Haunschild PR, Phillips DJ (2004) Friends or strangers? Firm-specific uncertainty, market uncertainty, and network partner selection. Organ Sci 15(3):259-275

Benjamin BA, Podolny JM (1999) Status, quality, and social order in the California wine industry. Adm Sci Q 44(3):563-589

Burt RS (1992) Structural holes. Harvard University Press, Cambridge

Busenitz LW, Fiet JO, Moesel DD (2005) Signaling in venture capitalist-new venture team funding decisions: does it indicate long-term venture outcomes? Entrep Theory Pract 29(1):1-12

Cameron S (2002) The economics of partner out trading in sexual markets. J Bioecon 4(3):195-222

Casciaro T, Piskorski MJ (2005) Power imbalance, mutual dependence, and constraint absorption: a closer look at resource dependence theory. Adm Sci Q 50(2):167-199

Caves RE, Porter ME (1977) From entry barriers to mobility barriers: conjectural decisions and contrived deterrence to new competition. Q J Econ 91(2):241-262

Chung S, Singh H, Lee K (2000) Complementarity, status similarity and social capital as drivers of alliance formation. Strateg Manag J 21(1):1-22

Das TK, Teng B-S (1998) Between trust and control: developing confidence in partner cooperation in alliances. Acad Manag Rev 23(3):491-512

Doz Y (1996) The evolution of cooperation in strategic alliances: initial conditions or learning processes? Strateg Manag J 17(S1):55-83

Dyer JH (1996) Does governance matter? Keiretsu alliances and asset specificity as sources of Japanese competitive advantage. Organ Sci 7(6):649-666

Dyer JH, Hatch NW (2006) Relation-specific capabilities and barriers to knowledge transfers: creating advantage through network relationships. Strateg Manag J 27(8):701-719

Dyer JH, Singh H (1998) The relational view: cooperative strategy and sources of interorganizational competitive advantage. Acad Manag Rev 23:660-679

Eisenhardt KM, Schoonhoven C (1996) Resource-based view of strategic alliance formation: strategic and social effects in entrepreneurial firms. Organ Sci 7(2):136-150

Fichman M, Levinthal DA (1991) Honeymoons and the liability of adolescence: a new perspective on duration dependence in social and organizational relationships. Acad Manag Rev 16(2):442-468

Financial Times Deutschland (2012) Peugeot lässt BMW im Stich. 22 June

Folta TB (1998) Governance and uncertainty: the tradeoff between administrative control and commitment. Strateg Manag J 19(11):1007-1028

Fombrun C, Shanley M (1990) What's in a name? Reputation building and corporate strategy. Acad Manag J 33(2):233-258

Gale D, Shapley LS (1962) College admissions and the stability of marriage. Am Math Mon 69(1):9-15

Gimeno J, Folta TB, Cooper AC, Woo CY (1997) Survival of the fittest? Entrepreneurial human capital and the persistence of underperforming firms. Adm Sci Q 42(4):750-783

Granovetter M (1985) Economic action and social structure: the problem of embeddedness. Am J Sociol 91:481-510

Greve HR, Baum JAC, Mitsuhashi H, Rowley TJ (2010) Built to last but falling apart: cohesion, friction, and withdrawal from interfirm alliances. Acad Manag J 53(2):302-322

Greve HR, Mitsuhashi H, Baum JAC (2013) Greener pastures: outside options and strategic alliance withdrawal. Organ Sci 24(1):79-98

Gulati R (1995a) Does familiarity breed trust? The implications of repeated ties for contractual choice in alliances. Acad Manag J 38(1):85-112

Gulati R (1995b) Social structure and alliance formation patterns: a longitudinal analysis. Adm Sci Q 40(4):619-652

Gulati R (1999) Network location and learning: the influence of network resources and firm capabilities on alliance formation. Strateg Manag J 20(5):397-420

Gulati R, Gargiulo M (1999) Where do interorganizational networks come from? Am J Sociol 104(5):1439-1493

Gulati R, Singh H (1998) The architecture of cooperation: managing coordination costs and appropriation concerns in strategic alliances. Adm Sci Q 43(4):781-814

Gulati R, Westphal JD (1999) Cooperative or controlling? The effects of CEO-board relations and the content of interlocks on the formation of joint ventures. Adm Sci Q 44(3):473-506

Gulati R, Nohria N, Zaheer A (2000) Strategic networks. Strateg Manag J 21(3):203-215

Gulati R, Lavie D, Madhavan R (2011) How do networks matter? The performance effects of interorganizational networks. Res Organ Behav 31:207-224 
Hagedoorn J, Sadowski B (1999) The transition from strategic technology alliances to mergers and acquisitions: an exploratory study. J Manag Stud 36(1):87-107

Harrigan KR (1986) Matching vertical integration strategies to competitive conditions. Strateg Manag $\mathrm{J}$ 7(6):535-555

Hitt MA, Ahlstrom D, Dacin MT, Levitas E, Svobodina L (2004) The institutional effects on strategic alliance partner selection in transition economies: China vs Russia. Organ Sci 15(2):173-185

Hoffmann WH (2005) How to manage a portfolio of alliances. Long Range Plan 38(2):121-143

Hoffmann WH, Neumann K, Speckbacher G (2010) The effect of interorganizational trust on make-orcooperate decisions: disentangling opportunism-dependent and opportunism-independent effects of trust. Eur Manag Rev 7(2):101-115

Hollander EP (1958) Conformity, status, and idiosyncrasy credit. Psychol Rev 65(2):117-127

Inkpen AC, Beamish PW (1997) Knowledge, bargaining power, and the instability of international joint ventures. Acad Manag Rev 22(1):177-202

Janney JJ, Folta TB (2003) Signaling through private equity placements and its impact on the valuation of biotechnology firms. J Bus Ventur 18(3):361-380

Jensen M (2006) Should we stay or should we go? Accountability, status anxiety, and client defections. Adm Sci Q 51(1):97-128

Jovanovic B (1979) Job matching and the theory of turnover. J Polit Econ 87(5):972-990

Kenis P, Knoke D (2002) How organizational field networks shape interorganizational tie-formation rates. Acad Manag Rev 27(2):275-293

Kogut B (1988) Joint ventures: theoretical and empirical perspectives. Strateg Manag J 9(4):319-332

Kogut B (1989) The stability of joint ventures: reciprocity and competitive rivalry. J Ind Econ 38(2):183-198

Kogut B (1991) Joint venture and the option to expand and acquire. Manag Sci 37(1):19-33

Kogut B, Zander U (1996) What do firms do? Coordination, identity, and learning. Organ Sci 7(5):502-518

Koza MP, Lewin AY (1998) The co-evolution of strategic alliances. Organ Sci 9(3):255-264

Larson A (1992) Network dyads in entrepreneurial settings: a study of the governance of exchange relationships. Adm Sci Q 37(1):76-104

Lavie D (2006) The competitive advantage of interconnected firms: an extension of the resource-based view. Acad Manag Rev 31(3):638-658

Lavie D (2007) Alliance portfolios and firm performance: a study of value creation and appropriation in the US software industry. Strateg Manag J 28(12):1187-1212

Levinthal DA, Fichman M (1988) Dynamics of interorganizational attachments: auditor-client relationships. Adm Sci Q 33(3):345-369

Logan JA (1996) Opportunity and choice in socially structured labor markets. Am J Sociol 102(1):114-160

Luo Y (2001) Antecedents and consequences of personal attachment in cross-cultural cooperative ventures. Adm Sci Q 46(2):177-201

Lynn FB, Podolny JM, Tao L (2009) A sociological (de)construction of the relationship between status and quality. Am J Sociol 115(3):755-804

Makino S, Chan CM, Isobe T, Beamish PW (2007) Intended and unintended termination of international joint ventures. Strateg Manag J 28(11):1113-1132

Marsden PV (1981) Introducing influence processes in a system of collective decisions. Am J Sociol 86(6):1203-1235

Mellewigt T, Decker C (2014) Costs of partner search and selection in strategic alliances. J Bus Econ 84(1):71-97

Milgrom P, Roberts J (1990) The economics of modern manufacturing: technology, strategy, and organization. Am Econ Rev 80(3):511-528

Milgrom P, Roberts J (1995) Complementarities and fit: strategy, structure, and organizational change in manufacturing. J Acc Econ 19(2-3):179-208

Mitsuhashi H, Greve HR (2009) A matching theory of alliance formation and organizational success: complementarity and compatibility. Acad Manag J 52(5):975-995

Montgomery CA, Wernerfelt B (1988) Diversification, Ricardian rents, and Tobin's q. RAND J Econ 19(4):623-632

Parkhe A (1993) Strategic alliance structuring: a game theoretic and transaction cost examination of interfirm cooperation. Acad Manag J 36(4):794-829 
Parmigiani A, Mitchell W (2009) Complementarity, capabilities, and the boundaries of the firm: the impact of within-firm and interfirm expertise on concurrent sourcing of complementary components. Strateg Manag J 30(10):1065-1091

Peng MW, Shenkar O (2002) Joint venture dissolution as corporate divorce. Acad Manag Perspect 16(2):92-105

Pfeffer J (1972) Merger as a response to organizational interdependence. Adm Sci Q 17(3):218-228

Pfeffer J, Salancik G (1978) The external control of organizations: a resource dependence perspective. Harper and Row Publishers, New York

Phillips DJ, Zuckerman EW (2001) Middle-status conformity: theoretical restatement and empirical demonstration in two markets. Am J Sociol 107(2):379-429

Podolny JM (1993) A status-based model of market competition. Am J Sociol 98(4):829-872

Podolny JM (1994) Market uncertainty and the social character of economic exchange. Adm Sci Q 39(3):458-483

Podolny JM, Phillips DJ (1996) The dynamics of organizational status. Ind Corp Change 5(2):453-471

Polanyi M (1967) The tacit dimension. Routledge and Kegan Paul Ltd, London

Poppo L, Zenger T (2002) Do formal contracts and relational governance function as substitutes or complements? Strateg Manag J 23(8):707-725

Porter ME (1980) Competitive strategy. Free Press, New York

Powell WW, Koput KW, Smith-Doerr L (1996) Interorganizational collaboration and the locus of innovation: networks of learning in biotechnology. Adm Sci Q 41(1):116-145

Reuer JJ, Ariño A (2002) Contractual renegotiations in strategic alliances. J Manag 28(1):47-56

Reuer JJ, Zollo M (2005) Termination outcomes of research alliances. Res Policy 34:101-115

Reuer JJ, Zollo M, Singh H (2002) Post-formation dynamics in strategic alliances. Strateg Manag J 23(2):135-151

Reuer JJ, Ariño A, Mellewigt T (2006) Entrepreneurial alliances as contractual forms. J Bus Ventur 21(3):306-325

Ring PS, Van de Ven AH (1994) Developmental processes of cooperative interorganizational relationships. Acad Manag Rev 19(1):90-118

Robertson TS, Gatignon H (1998) Technology development mode: a transaction cost conceptualization. Strateg Manag J 19(6):515-531

Roth A, Sotomayor M (1990) Two-sided matching. A study in game-theoretic modeling and analysis. Cambridge University Press, Cambridge

Rowley TJ, Greve HR, Rao H, Baum JAC, Shipilov AV (2005) Time to break up: the social and instrumental antecedents of exit from interfirm exchange cliques. Acad Manag J 48(3):499-520

Santoro MD, McGill JP (2005) The effect of uncertainty and asset co-specialization on governance in biotechnology alliances. Strateg Manag J 26(13):1261-1269

Seabright MA, Levinthal DA, Fichman M (1992) Role of individual attachments in the dissolution of interorganizational relationships. Acad Manag J 35(1):122-160

Simon HA (1955) A behavioral model of rational choice. Q J Econ 69(1):99-118

Simon HA (1978) Rationality as process and as product of thought. Am Econ Rev 68(2):1-16

Simon CJ, Warner JT (1992) Matchmaker, matchmaker: the effect of old boy networks on job match quality, earnings, and tenure. J Labor Econ 10(3):306-329

Singh K, Mitchell W (1996) Precarious collaboration: business survival after partners shut down or form new partnerships. Strateg Manag J 17:99-115

Stuart TE, Hoang H, Hybels RC (1999) Interorganizational endorsements and the performance of entrepreneurial ventures. Adm Sci Q 44(2):315-349

Sutcliffe KM, Zaheer A (1998) Uncertainty in the transaction environment: an empirical test. Strateg Manag J 19(1):1-23

Szulanski G (1996) Exploring internal stickiness: impediments to the transfer of best practice within the firm. Strateg Manag J 17(S2):27-43

Tanriverdi H, Venkatraman N (2005) Knowledge relatedness and the performance of multibusiness firms. Strateg Manag J 26(2):97-119

Teece DJ (1992) Competition, cooperation, and innovation: organizational arrangements for regimes of rapid technological progress. J Econ Behav Organ 18(1):1-25

Todd PM (1997) Searching for the next best mate. In: Conte R, Hegelsmann R, Terna P (eds) Simulating social phenomena. Springer-Verlag, Berlin, pp 419-436

Tyler BB, Kevin Steensma H (1995) Evaluating technological collaborative opportunities: a cognitive modeling perspective. Strateg Manag J 16(S1):43-70 
Uzzi B (1997) Social structure and competition in interfirm networks: the paradox of embeddedness. Adm Sci Q 42:35-67

Vissa B (2011) A matching theory of entrepreneurs' tie formation intentions and initiation of economic exchange. Acad Manag J 54(1):137-158

Walker G, Weber D (1984) A transaction cost approach to make-or-buy decisions. Adm Sci Q 29(3):373-391

Walker G, Weber D (1987) Supplier competition, uncertainty, and make-or-buy decisions. Acad Manag J 30:589-596

Walker G, Kogut B, Shan W (1997) Social capital, structural holes and the formation of an industry network. Organ Sci 8(2):109-125

Washington M, Zajac EJ (2005) Status evolution and competition: theory and evidence. Acad Manag J 48(2):282-296

Williamson OE (1975) Markets and hierarchies: analysis and antitrust implications. Free Press, New York

Williamson OE (1979) Transaction-cost economics: the governance of contractual relations. J Law Econ 22(2):233-261

Williamson OE (1981) The economics of organization: the transaction cost approach. Am J Sociol 87(3):548-577

Williamson OE (1985) The economic institutions of capitalism. Free Press, New York

Zajac EJ, Olsen CP (1993) From transaction cost to transaction value analysis: implications for the study of inter-organizational strategies. J Manag Stud 30(1):131-145

Publisher's Note Springer Nature remains neutral with regard to jurisdictional claims in published maps and institutional affiliations. 